\title{
PERFIL E ATUAÇÃO DE PSICÓLOGOS NOS CENTROS DE REFERÊNCIA EM SAÚDE DO TRABALHADOR
}

\author{
PERFIL Y DESEMPEÑO DE PSICÓLOGOS EN CENTROS DE \\ REFERENCIA DE SALUD DEL TRABAJADOR
PSYCHOLOGISTS' PROFILE AND PERFORMANCE ON WORKER'S HEALTH REFERENCE CENTER

\author{
Isabel Lopes dos Santos Keppler ${ }^{1}$ e Oswaldo Hajime Yamamoto ${ }^{1}$ \\ ${ }^{1}$ Universidade Federal do Rio Grande do Norte, Natal/RN, Brasil
}

\begin{abstract}
RESUMO: O campo da Saúde do Trabalhador (ST) se consolidou como política pública no Brasil a partir da Constituição Federal (1988) e, em 2002, os Centros de Referência em Saúde do Trabalhador (CEREST) são apontados como principal política. O objetivo deste estudo foi fazer mapeamento nacional e análise do perfil e atuação dos psicólogos que atuam nos CERESTs. Para tanto, realizou-se um questionário online contendo perguntas abertas e fechadas com psicólogos que atuam nos CERESTs, em que obtivemos 48 respostas. Analisando a formação, abordagens teóricas e outras questões vinculadas ao emprego do psicólogo no CEREST, verificou-se que há limites desde a formação à prática cotidiana, que dificulta uma atuação mais alinhada com as premissas do campo da Saúde do Trabalhador. Verificou-se a necessidade de resgatar alguns princípios da ST, como o protagonismo dos trabalhadores, aprimorar a formação na área e avançar na construção de uma rede, rompendo com o isolamento hoje presente nos CERESTs.

PALAVRAS-CHAVE: Atuação do psicólogo; Saúde do trabalhador; Política pública.
\end{abstract}

RESUMEN: El campo de la Salud del Trabajador (ST) se consolidó como política pública en Brasil a partir de la Constitución Federal (1988), y, en 2002, los Centros de Referencia en Salud del Trabajador (CEREST) son designados como política principal. El objetivo de este estudio fue realizar un mapeo nacional y análisis del perfil y desempeño de los psicólogos que laboran en los CEREST. Para ello, se realizó un cuestionario online de preguntas abiertas y cerradas con psicólogos que laboran en los CEREST, en el que obtuvimos 48 respuestas. Analizando la formación, los enfoques teóricos y otras cuestiones relacionadas con el empleo del psicólogo en el CEREST, se encontró que existen límites desde la formación a la práctica diaria, lo que dificulta actuar más acorde con las premisas del campo de la Salud del Trabajador. Existía la necesidad de recuperar algunos principios de la ST, como el protagonismo de los trabajadores, mejor formación en el área y avanzar en la construcción de una red, rompiendo con el aislamiento presente en los CEREST en la actualidad.

PALABRAS-CLAVE: Atuación del psicólogo; Salud del trabajador; Política pública.

ABSTRACT: The Worker's Health (WF) field was consolidated as a public policy in Brazil since the Federal Constitution (1988) and, in 2002, the Worker's Health Reference Center (CEREST) was designated as its main programme. This study's aim was to do a national survey and analysis of the profile and performance of psychologists who work in CEREST. For that matter, we obtained 48 replies to an online questionnaire that contained open and closed questions from psychologists working in CERESTs. Analyzing the qualification, the theoretical approaches and other issues related to the psychologist's job in CEREST, it was verified that there are limits ranging from the qualification to the daily practice, which makes it difficult to perform more in line with the Worker's Health field premises. This showed the need to rescue some WH's principles, such as the workers' lead role, and improving qualification in the area and advancing in the construction of a network, breaking with the isolation currently present in the CERESTs.

KEYWORDS: Psychologist's performance; Worker's health; Public policy. 


\section{Introdução}

Analisando em uma perspectiva de interesses de classe, a Psicologia nasce, se desenvolve, se consolida, e continua até hoje, enquanto projeto hegemônico, defendendo aos interesses da classe dominante (Lacerda, 2013).

Tal constatação apresenta-se como uma triste realidade em um contexto em que o trabalho, categoria fundante do ser social, que garante a produção e reprodução da vida humana, no modo de produção capitalista vigente assume também um caráter alienante e degradante (Lourenço, 2013, p. 185).

Os dados sobre as doenças e acidentes de trabalho apontam, por si só, a necessidade de os psicólogos atentarem mais para esse campo. De acordo com a Organização Internacional do Trabalho (ILO, 2019), estima-se 2.78 milhões de mortes por acidentes e doenças no trabalho e 374 milhões de acidentes não fatais. Mas isso se torna ainda mais relevante para o campo psi em um contex to de expectativa social por respostas em torno da saúde mental relacionada ao trabalho (Jacques, 2007; Paparelli, Sato, \& Oliveira, 2011; Sato \& Bernardo, 2005; Silva, Bernardo, \& Souza, 2016).

Faz-se necessário, portanto, refletir a quem a profissão vem servindo. O campo da Saúde do Trabalhador (ST) explicita um posicionamento diante dos interesses distintos entre classe dominante e classe trabalhadora (Imbrizi, Keppler, \& Vilhanueva, 2013, p.303).

Em um aspecto histórico, nas indústrias e, em seguida, nas organizações em geral, a Psicologia se insere com o objetivo de exercer "controle da subjetividade dos trabalhadores" (Heloani, 2005, p. 300), mediante o desenvolvimento de "técnicas de gerência" e outras formas para otimizar a produção. A seleção de pessoal é uma prática presente mesmo antes da regulamentação da profissão, na década de 1930 com o processo de industrialização, e contou com a contribuição da ciência psicológica para selecionar os que melhores se ajustam no processo produtivo.

A formação em Psicologia era marcada por esse perfil, que passou por um crescimento repentino, superior a 250\% entre a década de 1960-1970 (Coelho-Lima, 2013), mediante a expansão universitária da Reforma Universitária de 1968. Apesar de o contexto histórico ser de efervescência política, os primeiros anos da profissão da Psicologia não são marcados pelo debate sobre seus rumos (Yamamoto, 2007), de modo que a formação era "blindada" com um modelo tradicional. Até então, a Psicologia esteve inserida, basicamente, no contexto escolar, das organizações, além da tradicional área clínica, direcionada para as classes médias e mais abastadas. Nessas áreas, tratou-se de "psicologizar" os problemas sociais (Dimenstein, 2001), e sua função, grosso modo, era de adaptação do sujeito ao ambiente - ainda que este fosse o mais perverso.

É somente no período final da ditadura que a Psicologia passa a debater de forma mais profunda acerca de seus rumos. Segmentos da Psicologia passam a discutir a profissão e questionar suas práticas. O tema do "compromisso social” (Bock, 1999) é expressão disso. Esse não é um processo isolado que se fez presente no interior da Psicologia: a profissão é afetada pela conjuntura e se politiza (Lacerda, 2013; Yamamoto, 2007) - o que não significa que antes não havia uma política, ainda que camuflada por um discurso neutro e tecnicista.

Esse processo de politização envolve a tomada dos sindicatos e sistema-conselho por parte de um setor mais crítico e combativo, mas também no envolvimento concreto nas lutas sociais, em especial no movimento da saúde pela Reforma Sanitária (Lacerda, 2013). 
Concomitante ao debate do "compromisso social" que atinge uma parcela da categoria, a profissão passa por um processo de expansão que envolve a atuação nas políticas públicas, a inserção do psicólogo no campo do trabalho em uma perspectiva alinhada com os interesses da classe trabalhadora. Nesse mesmo contexto em que se problematiza a Psicologia e se buscam alternativas ao modelo tradicional, alguns profissionais se engajam na construção do campo da Saúde do Trabalhador.

A Saúde do Trabalhador representa a ruptura com uma prática de "influência positivista, monocausal e redutora" (Lacaz, 1996, p. 410). Origina-se no Movimento Operário Italiano (MOI) da década de 1960, quando os próprios trabalhadores passam a formular princípios, metodologia e intervenção partindo do saber presente no cotidiano do chão da fábrica e representa um primeiro momento de convergência entre a análise crítica espontânea da classe operária sobre suas condições de trabalho e a necessidade, que os técnicos sentem, de colocar à disposição da classe operária todo o seu conhecimento científico, utilizado minimamente em benefício do homem (Oddone et al., 1986, p. 17).

No Brasil, o campo da Saúde do Trabalhador começa a ser discutido desde a década de 1970, no âmbito das pesquisas, sobretudo com estudos da medicina preventiva e saúde pública; no movimento sindical, que se fortalece com a consolidação do direito à livre organização e a criação do Departamento Intersindical de Estudos e Pesquisas de Saúde e dos Ambientes de Trabalho (DIESAT), em 1980; no movimento da Reforma Sanitária e nas importantes resoluções da VIII Conferência Nacional de Saúde, que tem como desdobramento a realização da I Conferência Nacional em Saúde dos Trabalhadores no mesmo ano (1986); e na experiência prática da criação dos Programas de Saúde do Trabalhador (PST) e primeiros Centros de Referência em Saúde do Trabalhador, em especial em São Paulo em meados da década de 1980 (Minayo-Gomez, 201 1, p. 24).

No início da década de 1980 ocorrem as primeiras experiências práticas de atuação do psicólogo em Programas de Saúde do Trabalhador (PSTs), antes da criação da Rede de Atenção Integral à Saúde do Trabalhador (RENAST). Essas experiências ocorrem sem um arcabouço teórico próprio sobre ST ou mesmo saúde em geral. A saúde - e a Saúde do Trabalhador - não faziam parte da formação graduada, tampouco havia pesquisas da categoria sobre o tema. Até então, o que havia em relação à Psicologia e Trabalho se concentrava no campo Organizacional.

Ao final de 2002, com a Portaria do Ministério da Saúde de n. 1.679, a RENAST é criada e adotada como principal estratégia da Política Nacional em Saúde do Trabalhador, algo considerado um marco na consolidação da política pública em ST no Brasil. Com essa iniciativa, foi atribuída ao CEREST a função de "polo irradiador" das políticas, enquanto unidade de referência, promovendo ações relacionadas à vigilância, assistência, educação em saúde e produção de informação em saúde do trabalhador.

A atuação nos PSTs, CERESTs e demais organismos da política voltada à Saúde do Trabalhador que foram criados nessa mesma perspectiva tornou-se espaço de formulação para pesquisas a partir, sobretudo, do relato, reflexão e sistematização de experiências de intervenção.

Em 2008, o Conselho Federal de Psicologia publica o documento elaborado pelo Centro de Referência Técnica em Psicologia e Políticas Públicas que foi revisado recentemente (Conselho Federal de Psicologia - CFP, 2019), "Saúde do Trabalhador no âmbito da Saúde Pública: referências para a atuação do(a) psicólogo(a)”. Esse material, que se apresenta como 
uma espécie de "manual" do psicólogo no campo da Saúde do Trabalhador, sistematiza as atividades deste profissional no campo. Antes disso, em 2006, já houve um artigo em que se sistematizou as atividades do Psicólogo (Sato et al., 2006).

Esse mesmo documento do CFP afirma que "a relação trabalho/subjetividade ainda não foi devidamente reconhecida nesse contexto [formação do psicólogo], o que representa uma séria barreira para a atuação desse profissional em todas as áreas, sobretudo no campo da Saúde do Trabalhador" (CFP, 2019, p. 64). Fato é que, ainda que os temas de compromisso social e outras perspectivas tenham ganhado espaço na psicologia, não houve necessariamente uma virada no que diz respeito ao projeto da profissão, mas sim uma ampliação do fazer psicológico. Hoje é possível observar um grande ecletismo, tanto no que tange às abordagens teórico-metodológicas como nas áreas de atuação (Lacerda, 2013).

Embora na última década observe-se um movimento em incorporar novas disciplinas ou ampliar adicionando novas concepções, não há um abandono das bases teóricas tradicionais que, muitas vezes, por serem as mais consolidadas e ainda maioria entre o corpo docente, terminam por, em síntese, perpetuar o projeto hegemônico. Isso reflete em um contex to que não diz respeito unicamente à perspectiva ideológica do profissional mas como consequência de uma formação que reforça o modelo "tradicional" da Psicologia.

A atuação do psicólogo no CEREST ocorre nesse cenário de demanda (das empresas, do Estado e mesmo dos trabalhadores, nos sindicatos) para que as áreas psi respondam aos impactos do trabalho (e da ausência, no caso do desemprego) na saúde mental, mas também por uma necessidade de ampliação das áreas de atuação do profissional mediante a expansão dos cursos de graduação. A materialização dessa atuação, atravessada pelas questões apresentadas até então, estão presentes na pesquisa realizada em 2015.

\section{Procedimentos metodológicos}

Este estudo é parte de uma pesquisa que se propôs compreender de que forma se articula a atuação do psicólogo no CEREST com o campo teórico e político da saúde do trabalhador. Para tanto, realizou-se um mapeamento dos psicólogos que atuam nos CERESTs.

O mapeamento exigiu um árduo trabalho, já antecipado por outras publicações sobre CEREST que relatam o fato de muitos equipamentos serem "virtuais" ou com baixo grau de estruturação (Jacques, 2009; Lacaz, Machado, \& Porto, 2002 ${ }^{1}$ ).Buscou-se, por exaustão, alcançar todos os CERESTs que, segundo dados do Ministério da Saúde no período da entrevista (2015), eram 200 unidades em todo o Brasil. O contato foi estabelecido através dos números telefônicos que constam no Cadastro Nacional de Estabelecimentos de Saúde (CNES) e no sítio eletrônico da RENAST. Na ausência de telefone ou quando este estava desatualizado, contataram-se secretarias de saúde dos respectivos estados e buscou-se na web. Não foi possível alcançar 41, em que não se sabe ao certo quantos apenas não possuem telefone ou esse é indisponível na rede, e quantos de fato foram desabilitados ou ainda não foram ativados. 
Figura 1. Mapeamento dos CERESTs contatados e retornos obtidos.

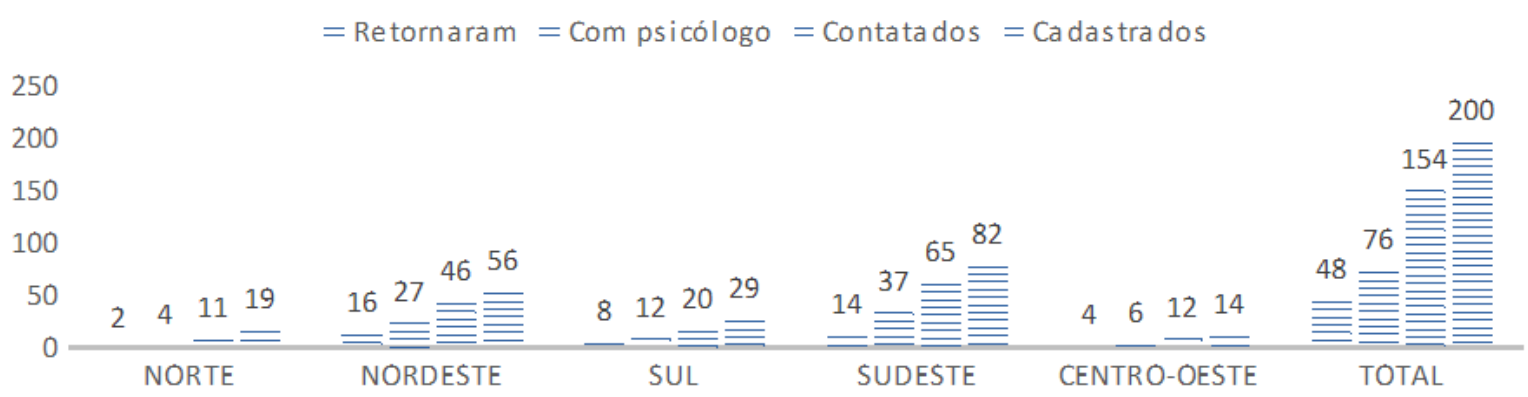

Ao final, foi realizado contato com 154 equipamentos (ver Figura 1). Em 76 unidades foi confirmado que havia pelo menos um psicólogo (49,5\%). Em dez desses CERESTs, embora tenha sido confirmado que havia profissional, em nenhuma das tentativas (de três a cinco para cada um deles) foi possível acessá-lo - seja por estar em viagem, greve, licença ou por não possuírem uma agenda fixa na unidade de saúde.

O procedimento padrão foi contatar via telefone e questionar a presença ou não de psicólogo na equipe. Em caso afirmativo, perguntou-se ao psicólogo se gostaria de participar da pesquisa. Aos que aceitaram participar, foi enviado um questionário online com 32 perguntas organizadas em quatro blocos, com questões abertas e fechadas: perfil do psicólogo, funcionamento do CEREST, condições de trabalho do psicólogo e atividades do psicólogo. Por fim, 48 psicólogos responderam ao questionário, sendo dois de um mesmo equipamento (ou seja, as respostas correspondem ao trabalho realizado em 47 CERESTs).

Referente à análise dos dados, primeiro fez-se estatística descritiva para as perguntas fechadas. No caso das questões abertas, realizaram-se categorias de análise. Em seguida, agrupou-se em tópicos para discussão dos resultados.

\section{Resultados e discussão}

Os psicólogos respondentes do questionário, em geral, reafirmam aspectos da profissão já apresentadas em pesquisas anteriores, como o fato de ser uma categoria feminina (Lhullier\&Roslindo, 2013); com mais de um local de trabalho e carga horária semanal superior a $30 \mathrm{~h}$.

Uma particularidade da profissão atuante no CEREST em relação ao cenário geral do psicólogo no setor público é uma disparidade maior entre estatu tários e celetistas. Enquanto no setor público em geral 50\% são estatutários e 21,8\% celetistas (Macêdo, Heloani, \& Cassiolato, 2010), a pesquisa apontou para um quadro em que $73 \%$ são estatutários e 19\% celetistas, no caso dos psicólogos do CEREST. Esse resultado aproxima do apresentado no $2^{\circ}$ Inventário RENAST de 2010 , em que consta que 66,6\% dos funcionários do CEREST são estatutários e 15,7\% celetistas. Essa realidade contrapõe-se positivamente à presente na atenção básica e do SUS em geral, onde já prevalece o contrato via CLT ou demais formas de contrato precário (Machado et al., 2013), mediante política de terceirização da saúde. Entende-se que os contratos estatutários permitem maior estabilidade para o profissional e, ao mesmo tempo, tendem a possibilitar uma continuidade maior no serviço, produzindo impactos positivos também na atuação. 
A remuneração e os direitos trabalhistas não foram abordados diretamente no questionário, mas foi um tema levantado por alguns profissionais na questão aberta. Além de ter sido abordado por alguns, o fato de 50\% terem mais de uma ocupação é um dado relevante para discussão. A Figura 2 apresenta a distribuição das horas semanais de trabalho e quantidade de ocupações.

\section{Figura 2. Relação carga horária e Empregos do psicólogo}

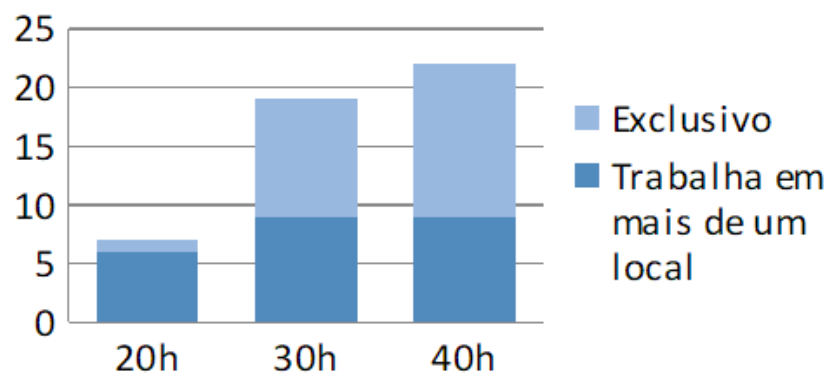

O fato de trabalhar menos horas no CEREST não necessariamente implica melhores condições de trabalho. Como consta na figura 2, 85,7\% dos que trabalham 20 h atuam em pelo menos mais um local. Mesmo entre os psicólogos que trabalham 30h, reivindicação histórica da categoria, uma parcela significante trabalha em mais de um local.

Segundo Macedo, Heloani e Cassiolato (2010), cerca de 2/3 dos psicólogos possuem mais de um emprego. Gondim, Bastos e Peixoto (2010) formulam como hipóteses para se inserir em mais de uma área simultaneamente a expansão da profissão, mas também a insatisfação com a baixa remuneração ou não identificação com área de atuação. Com relação a isso, o tópico sobre formação e capacitação e abordagem teórica e prática trazem dados para refletir sobre a identificação do profissional com a área de atuação em saúde do trabalhador.

A questão de ter mais de um emprego se torna ainda mais relevante quando consideramos o aspecto de se tratar, significativamente, de mulheres $(85,4 \%)$. A pesquisa de Lhullier e Roslindo (2013) aponta o fato de que a "dupla jornada de trabalho", considerando as tarefas domésticas, limitam "a inserção laboral dessas profissionais" (p. 106). Enquanto 90\% das mulheres despendem cerca de 27 horas semanais com tarefas domésticas sem remuneração, são 45\% os homens que se envolvem com aproximadamente 10 horas (Diogo \& Coutinho, 2013). Assim, essa sobrecarga deve ser considerada, para além de a maioria ter mais de um emprego.

\section{Formação e Capacitação}

Perguntou-se se o respondente avalia que sua graduação deveria ter sido mais adequada, e $67 \%$ consideram que sim. Desses, 37,5\% (doze psicólogos) colocaram a necessidade de um tópico específico sobre "Saúde do Trabalhador". Mais ainda, 60\% apontaram a necessidade de discutir saúde mental e trabalho, políticas públicas e SUS etc. 
Importante destacar que a maioria (70\%) fez a graduação há mais de dez anos, acompanhado de 25\% que graduaram entre cinco e dez anos. Segundo Coelho-Lima (2013), em seu estudo sobre Psicologia do Trabalho e das Organizações na formação do psicólogo, há uma tendência na última década de essa área direcionar-se para a discussão sobre saúde e qualidade de vida.

O documento elaborado pelo CREPOP (2008) sinaliza alguns itens que devem constar na formação do psicólogo (CREPOP, 2008, pp. 45-46). Tais itens convergem com demandas levantadas nas respostas dos psicólogos:

Apesar de ter tido uma boa formação em psicologia do trabalho, faltaram aspectos relativos a políticas públicas em saúde do trabalhador. (R25)

Na graduação não foi apresentado saúde coletiva, saúde do trabalhador e no CEREST ainda não foi possivel fazer especialização em ST. (R42)

Segundo Coelho-Lima (2013), um dos fatores que levaram à inserção do conteúdo da Psicologia do Trabalho na graduação está a absorção dos psicólogos no campo da Saúde do Trabalhador, mais especificamente nos CERESTs, mediante a sua criação e expansão. Então, a inserção dessas discussões no currículo parte da demanda do psicólogo que atua no contexto do trabalho, fazendo com que, muitas vezes, o tema se insira no currículo orientado à prática profissional, sem necessariamente inserir bases teóricas que possam sustentar essa prática.

Também evidenciou, nas respostas, que temas relacionados ao campo da Saúde do Trabalhador deveriam servir para a formação do psicólogo em geral.

Da relevância da categoria trabalho como sendo central na vida das pessoas, do sofrimento e adoecimento ligados ao mundo do trabalho e também de uma abordagem epidemiológica e interdisciplinar e de vigilância em saúde e não somente nas doenças e no aspecto clínico individual. (R31)

Acredito que deveria ser trabalhada as categorias trabalho e subjetividade com mais ênfase em minha formação. (R34)

Os psicólogos citados acima reforçam a importância do profissional, em qualquer contex to de atuação, considerar a centralidade do trabalho, bem como o tema dos impactos na saúde mental dos trabalhadores, pelos motivos já elencados na introdução.

Para além das demandas para uma formação mais adequada na graduação, com relação à especialização, 41 afirmaram possuir alguma modalidade de formação pós-graduada (85,6\%), mas apenas dez possuem pelo menos uma especialização diretamente relacionada ao campo da Saúde do Trabalhador, e outros dez com temas que estão relacionados (Saúde Mental, SUS, trabalho, Psicologia Organizacional e do Trabalho). A maioria (21) possui uma ou mais especializações que não estão necessariamente vinculadas ao campo. Pelo menos 13 citaram mais de uma especialização, ou combinação especialização e mestrado, além de dois que possuem doutorado.

Não é possível constatar pelo questionário se a opção por especializações em outros temas que não saúde do trabalhador deriva do interesse em outras áreas ou da ausência de especializações específicas desse campo. 
Para além das especializações, 11 psicólogos alegaram não ter nenhum tipo de capacitação ofertada pelo CEREST até então (apenas um trabalhava no equipamento a menos de um ano).

Essa deficiência parece ser percebida por quem está no cotidiano do trabalho. O tema surgiu espontaneamente tanto como aspectos positivos, que garantem o bom funcionamento da unidade, quanto nos aspectos negativos. Referente aos aspectos positivos, o tema aparece em 16 respostas, seja dizendo que a equipe é capacitada ou que existe capacitação constante, sendo este o tópico mais citado. Nos aspectos negativos, foi citada sete vezes a ausência ou insuficiência de capacitação, como por exemplo:

Falta de formação, pois a saúde do trabalhador envolve um conhecimento especializado, técnico e interdisciplinar; muitos protocolos para "dominar" conhecimento e desenvolver intervenções e responder demandas. (R46)

Esse tema aparece como estratégia para melhorar a intervenção do psicólogo e no enfrentamento dos problemas presentes em sua atuação hoje. Houve 13 citações referentes à capacitação. Reitera-se aqui, a necessidade de capacitação em Saúde do Trabalhador para todo psicólogo que ingresse nos serviços de saúde. Além disso, capacitação que aborde temas referentes ao mundo do trabalho para psicólogos que atuam em unidades de saúde e no CEREST.

\section{Abordagem teórica e fundamentos da atuação}

Entende-se que a opção pela abordagem teórica está bastante relacionada com a formação e a capacitação. A formação, a especialização e a capacitação se refletem na prática do profissional, seja ao despertar o interesse (em especial no caso da formação), seja ao instrumentalizar, teoricamente e tecnicamente, o profissional.

No questionário, ao perguntar sobre abordagem teórica adotada, os resultados se aproximam de resultados de outros estudos sobre o trabalho do psicólogo (Gondim, Bastos, \& Peixoto, 2010), no que diz respeito à Psicanálise como escolha prioritária e na possibilidade de uso de duas ou mais abordagens.

Referente ao uso das duas abordagens, a combinação variou, com destaque para o uso de Psicanálise e Psicologia Sócio-Histórica, que foi apresentado três vezes. Para além dessas, a Psicanálise foi combinada com mais alguma abordagem mais seis vezes (em uma delas, pelo psicólogo que diz utilizar quatro abordagens). Assim, no total, foram 23 psicólogos (47,9\%) que citaram Psicanálise como uma das abordagens utilizadas, ao menos.

No estudo sobre áreas de atuação, atividades e abordagens teóricas do psicólogo brasileiro (Gondim, Bastos, \& Peixoto, 2010), a Psicanálise também se destaca como a abordagem metodológica preferencial dos trabalhadores da saúde.

Da mesma forma que na pergunta sobre especialização, não foi possível afirmar se tratar de uma opção preferencial por uma questão de escolha e identificação do profissional, ou se por uma ausência de especialização própria do campo da saúde do trabalhador. No entanto, é importante problematizar os limites de uma atuação de profissionais que se especializam em abordagens cujos pressupostos apontam para direções diversas ao que o campo se propõe. Por exemplo, abordagens tradicionais como a Psicologia Cognitivista ou Psicanálise fundamentam uma prática, convencionalmente orientada ao indivíduo, o que já 
produziria choques com a compreensão sobre Saúde do Trabalhador. Assim, à parte dessa questão preferencial de abordagem, que pode inclusive ser específica para cada profissional, permite-nos aqui trazer a reflexão sobre o impacto disso na atividade do psicólogo e, por consequência, no próprio atendimento do CEREST.

\section{Atividades do Psicólogo}

Sobre esse tema, solicitou-se que o psicólogo assinalasse as atividades que ele desenvolve e aquelas que sabe que o CEREST desenvolve. Esta última foi descartada diante da inconsistência dos dados. Também foram analisados nesse tópico elementos que apareceram nas questões abertas. As infor mações do questionário não permitem avaliarmos qualitativamente em que termos ocorrem.

Sobre as atividades assinaladas: coordenação (4), preenchimento de CAT (4), atendimento em grupo (17), triagem e nexo causal (19), notificação de agravo (25), divulgação e organização de eventos (32), vigilância (31), atendimento individual de casos diretamente relacionados à saúde mental (28), atendimento individual de casos gerais (20), educação em saúde em instituições de saúde (38), educação em saúde em outras instituições (34), grupos de acolhimento/terapêutico (17), outros (9).

Observa-se a predominância de atividades de educação em saúde e vigilância. As atividades de educação em saúde também foram as mais referenciadas quando solicitados a citarem uma intervenção em que alcançou parcialmente o seu objetivo. Os atendimentos individuais foram citados pela maioria dos psicólogos. Foram 28 psicólogos que assinalaram realizar atendimentos individuais, 8 assinalando exclusivamente casos relacionados a transtorno mental.

Foi solicitado aos respondentes que exemplificassem uma intervenção considerada exitosa. Seis psicólogos citaram alguma experiência que foi identificada diretamente com a prática de assistência; desses, a maioria trata de atendimento individual, com apenas um relato de experiência de grupo de LER/DORT.

Atendimento ao trabalhador com transtorno mental relacionado ao trabalho que não conseguia atendimento na rede de saúde. (R 10)

Agora voltado para a saúde mental vejo um caso o qual a trabalhadora sofria assédio moral desenvolveu síndrome do pânico e conseguimos orientá-la, afastá-la pelo INSS e depois a mesma conseguiu trabalhar em outro local. (R 14 )

Consegui estabilizar emocionalmente trabalhadores com algumas sessões e posteriormente conseguimos encaminhá-los para a continuidade do tratamento ora na rede, ora em consultas pactuadas pelo CEREST. (R29)

As respostas acima trazem à tona a discussão sobre o papel do CEREST e a preocupação sobre a atuação do psicólogo reproduzir práticas tradicionais em Psicologia. A R10 explicita como, por vezes, a assistência no CEREST não corresponde necessariamente a uma demanda especializada, mas à incapacidade de o SUS lidar com casos de saúde do trabalhador. Além do risco de apenas reproduzir uma lógica individualizante de cuidado em 
saúde, tal prática só é possível levando em consideração a subutilização do serviço; se fosse tomado como referência o atendimento individual de casos de assédio moral, por exemplo, e esses fossem encaminhados ao CEREST, tal equipamento sofreria uma superlotação.

Isso não significa que o atendimento individual não possa ser uma estratégia utilizada em casos particulares, que requerem um atendimento especializado. A resposta mostrada abaixo apresenta um atendimento individual articulado com outras ações do CEREST.

Trabalhadora recebida no grupo de acolhimento com queixa de sofrimento psíquico relacionado ao trabalho. Foi acolhida no grupo, atendida algumas vezes individualmente e encaminhada para tratamento. A queixa de assédio moral foi transformada numa ação de vigilância. Infelizmente, a empresa, sabedora da nossa visita, descaracterizou o ambiente onde ficava os trabalhadores à espera de lotação. (R26)

Esse exemplo também nos ajuda a pensar os desafios impostos nas ações de vigilância, atividade bastante citada nas diversas questões abertas. Nas questões fechadas, 39 assinalaram que o CEREST realiza ações vigilância e, dentre esses, em 31 os psicólogos participam.

A R26 citada anteriormente menciona um dos obstáculos vivenciados nas ações de vigilância, referente à dificuldade imposta pelas empresas fiscalizadas - seja barrando a entrada ou alterando o ambiente de trabalho no dia da inspeção.

Além da resistência das empresas, que a resposta acima e outra apontaram como um dado, dois psicólogos mencionaram explicitamente a ausência ou insuficiência de veículo como um elemento que interfere nas ações da vigilância. Nove abordaram especificamente a ação de vigilância ao relatarem uma intervenção, duas das quais relacionadas à saúde mental.

Vigilância em saúde do trabalhador, um caso específico de saúde mental em uma empresa Federal. (R6)

Atuação na vigilância em assédio moral no trabalho. (R18)

Há casos de intervenções pontuais e isoladas a partir de uma denúncia ou uma demanda ao serviço, como é o caso dos exemplos em que se articula assistência e vigilância. Na consolidação das ações de vigilância em saúde no SUS, constava uma preocupação em diferenciar-se do fazer burocrático e pontual do Ministério do Trabalho, que resultava em ações imediatistas. Na saúde pública, como consta na Portaria n. 3.120 de 01/07/98, a vigilância deve ser contínua e ter um caráter de "conhecer, pesquisar e analisar os fatores determinantes e condicionantes dos agravos à saúde relacionados aos processos e ambientes de trabalho".

Em estratégias para melhorar o serviço foram cinco respostas que citavam diretamente propostas para a vigilância. O tema da saúde mental e a demanda por formalizar um protocolo apareceram em uma das respostas como uma preocupação, bem como a necessidade de aumentar a equipe.

É necessário desenvolver estratégias de inspeção em saúde mental do trabalhador. (R45) 
Aumentar o número de psicólogos e psiquiatras nas equipes e participar das ações de vigilância. (R26)

Maior envolvimento com vigilância, sobretudo frente ao problema do assédio nas empresas. (R18)

Apontou-se, em aspectos negativos que interferem em uma boa atuação, o despreparo da equipe no que tange às ações de vigilância:

Falta de mais treinamento da equipe do CEREST, notadamente nas questões relacionadas à inspeção de ambientes de trabalho. (R13)

Novamente, o tema da importância da capacitação do campo é colocado em foco. No geral, as respostas aparentam reforçar a demanda para que sejam capazes de intervir nos impactos da saúde mental do trabalhador. Apesar de o questionário não nos permitir saber de que forma essas ações estão sendo executadas, é um dado interessante que os psicólogos citem como experiências em que alcançaram parcialmente seu objetivo mais casos de vigilância do que de assistência. Mais que isso, desses nove, quatro ao menos se referem a campanhas mais gerais.

Constata-se, portanto, referente à vigilância, que há uma expectativa, por parte do psicólogo, para que esses consigam intervir nos ambientes de trabalho no que diz respeito à saúde mental do trabalhador e isso convoca o psicólogo a capacitar a equipe e o serviço, mas também ser capacitado para tal ação. Reforça a preocupação presente em outros estudos de avaliação do CEREST referente às ações de vigilância reproduzirem a "lógica cartorial” (Santos \&Lacaz, 2011, p. 96). Uma forma de prevenir isso é a produção de dados, permitindo um planejamento das ações do CEREST que reflita ao máximo os problemas da região em relação a acidentes e mortes de trabalho.

A produção de dados e a notificação são práticas que competem ao profissional em saúde do trabalhador, além de contribuir para as ações de vigilância. Psicólogos de 25 CERESTs alegaram fazer notificação. O preenchimento da CAT, que alimenta os dados da Previdência e auxilia na aquisição do auxílio, foi assinalado como atividade de 16 CERESTs apenas e, entre eles, quatro psicólogos participam. Mais do que realizar notificação, é papel do CEREST orientar a rede a fazê-la, no intuito de produção de dados. No entanto, a falta de compreensão dos profissionais por um lado, e o acúmulo de funções, por outro, faz com que se reduza a mais uma tarefa burocrática. Agrava esse cenário nos casos de transtornos psíquicos.

Sobre envolver-se com a atividade de Educação, são 38 psicólogos que alegaram realizar para outras unidades de saúde. Com relação a outras instituições, são desenvolvidas em 34 CERESTs.

Havia também uma alternativa de divulgação e organização de eventos, que qualifica como uma forma de educação em saúde, e 31 psicólogos alegaram realizar. Foi espontaneamente citada por 11 psicólogos na questão sobre intervenções exitosas. Essas apresentaram como exemplos campanhas realizadas referentes a Burnout para profissionais da saúde, diminuição do trabalho infantil, seminários sobre saúde mental e trabalho etc. É a atividade mais realizada, inclusive em relação ao atendimento individual, mas as respostas não permitiram identificar de que forma tal formação é realizada. 
Sobre triagem no CEREST com estabelecimento de nexo causal, 19 alegaram realizar tal atividade. Em relação a estratégias, uma psicóloga apontou a necessidade de

Capacitação para elaboração de nexo causal em Saúde Mental, relacionando o processo saúde-doença a condicionantes sociais, em particular à organização do trabalho. (R22)

A dificuldade em estabelecer o nexo causal é a materialidade de uma lógica predominante na área 'psi', ainda centrada no indivíduo, que dificulta enxergar as relações sociais e o próprio processo de trabalho como determinantes. Segundo Sato e Bernardo (2005), "apesar de os problemas de Saúde Mental e Trabalho serem reconhecidos na CID 10, a sua notificação ainda representa um desafio para a saúde pública” (p. 872).

Essa dificuldade foi um tema que surgiu para os profissionais e apresentar saídas e respostas é uma medida urgente, considerando que estabelecer o nexo causal reflete diretamente nas demais atividades do psicólogo e do CEREST, tais como a notificação, produção de dados, assistência e vigilância.

\section{Conclusão}

A pesquisa permitiu traçar um panorama geral que pode auxiliar estudos posteriores para explorar os apontamentos apresentados. Referente aos dados colhidos sobre perfil dos psicólogos, o fato de ainda preservar uma parcela maior de profissionais contratados em regime estatutário é um elemento positivo, característica particular do CEREST. No entanto, o fator de se tratar de psicólogos com mais de uma ocupação além do CEREST, somado ao fato de ser uma categoria predominantemente feminina deve ser considerada ao compreender as condições de trabalho e do serviço.

$\mathrm{O}$ mesmo no que tange à formação. Percebe-se a necessidade de alinhar-se com o campo da Saúde do Trabalhador. Os profissionais da categoria que atuam no CEREST apresentam preocupações de como responder às demandas que surgem.

Por um lado, o fato de usarem diversas abordagens, e de as especializações terem pouca relação com o campo da Saúde do Trabalhador nos levanta a hipótese de que poucos profissionais que hoje se encontram atuando no CEREST possuem afinidade ou se identificam com o campo, resultando em um perfil de psicólogos que desempenharia a profissão no CEREST mais por uma questão de complemento da renda ou por estabilidade. Para isso se confirmar, seria necessário um estudo tratando objetivamente desta questão.

Para nós, interessa aqui menos a motivação, mas os efeitos de uma perspectiva que não responda às necessidades do serviço. Tal como Gondim, Bastos e Peixoto (2010) afirmam que "se o psicólogo se vê diante de situações novas de trabalho para as quais não se sente preparado, recorre ao modelo predominante que oferece status de referência, sem que ele avalie criticamente sua adequação para esta situação” (p. 182). Assim, a carência de uma formação permanente que instrumentalize e direcione os profissionais para uma prática coerente com o campo de atuação abre brecha para abordagens e técnicas que são até mesmo contraditórias e confrontam com a intervenção.

A vinculação a dois empregos poderia estar relacionada às condições precárias ou ao desestímulo que sente no CEREST - ou mesmo ambos. Seja por um motivo, ou por outro, 
isso se reflete na qualidade do serviço no que se refere ao tempo para preparar-se, ou mesmo por alguns aspectos que exigem maior tempo no CEREST, como o caso de viagens na área de abrangência.

Entende-se que o debate do compromisso social com as classes subalternas não implica, automaticamente, um compromisso com a transformação desse modo de organização societária desigual. Um exemplo disso é o caso de estudos e práticas que, ao valorizarem a "singularidade", em um discurso enaltecedor das relações "micropolíticas", convertem a desigualdade social inerente ao sistema em "questões sociais" dispersas e fragmentadas na vida cotidiana. Da mesma forma, a contradição capital-trabalho e sua condicionante relação de exploração passa a ficar diluída em “desigualdades” de gênero, de raça, sexuais (Sato et al., 2002, p. 78), perdendo até mesmo a força presente em reconhecer esses mecanismos de opressão como parte de um sistema que necessita dessa pluralidade.

No campo da produção científica, o não reconhecimento do papel central do trabalho e do modo de produção vigente no desenvolvimento dessas "questões sociais" e diferentes mecanismos de opressão, ou mesmo a diluição de sua centralidade como mais um elemento de análise para compreender os fenômenos, é um fator importante que resulta em reprodução da lógica dominante, ainda que seu objetivo seja o contrário.

No que tange à prática do psicólogo, tal problemática do compromisso social também impõe limites para além da opção ideológica do profissional, pois enquanto trabalho, a "sua reprodução na sociedade capitalista se justifica na medida em que, produzindo serviços que atendem a necessidades sociais, contribuem para o processo de reprodução e redistribuição de mais-valia" (Yamamoto, 2007, p. 35).

Dessa forma, ao buscar mapear quem são os psicólogos que atuam nos Centros de Referência em Saúde do Trabalhador, verifica-se a importância de refletir para além do aspecto ideológico do profissional. Abordando apenas dessa forma, corremos o risco de fazer uma análise centrada em uma perspectiva voluntarista, cuja pergunta central seria se o psicólogo é interessado e comprometido, ou não. Os dados trazidos nesse estudo trazem ao debate que condições estão sendo dadas para que esses psicólogos atuem em uma perspectiva que atente à centralidade do trabalho, na profissão em geral, mas também no CEREST, em que se verificou limites tanto na formação e capacitação como nas condições objetivas em que o psicólogo trabalha no CEREST.

Sobre as atividades, ainda que a maioria realize atendimento individual, estão também envolvidos com ações de vigilância e educação em saúde, algo positivo, a priori. No entanto, o método de questionário online nos impediu de obter uma descrição qualitativa sobre tais ações, o que dificulta a análise mais aprofundada.

Em suma, o questionário, embora consiga apresentar as atividades realizadas pelos psicólogos, não possibilita identificar, de forma precisa, o quão apropriados esses profissionais estão das premissas do campo. Também há respostas no questionário em que o que o psicólogo quer fazer e/ou o que o serviço da forma que está estruturado permite o psicólogo fazer sobrepõe ao que o campo se propõe ou não a realizar. Por exemplo, com relação às ações assistenciais. Dos 12 psicólogos que não assinalaram realizar grupos, atendimento ou qualquer outra assistência psicológica na unidade, quatro apontaram a falta de espaço para atendimentos como aspecto negativo e um está envolvido na coordenação da unidade. Quando apresentou como principal queixa a falta de sala para atendimento, verificou-se uma maior vinculação às demandas da atuação tradicional da psicologia, mais do que ao que o campo demanda. 
Se tomarmos como referência de atuação do psicólogo os exemplos de intervenção referentes a atendimentos individuais, o serviço do CEREST nunca será adequado. R20, por exemplo, cita como experiência positiva uma intervenção que articula assistência e vigilância

Uma trabalhadora de restaurante, que nos procurou quando, após afastamento por acidente de trabalho, sentiu-se vítima de assédio moral horizontal, foi atendida e orientada pela psicóloga, e também fui ao restaurante conversar e orientar o gerente. Parece que as dificuldades se esclareceram. (R20)

Ao mesmo tempo, aponta como estratégia para melhorar a atuação do psicólogo a divulgação

No meu caso acredito que tudo o que precisamos para o serviço de psicologia melhorar é divulgação. (R20)

Esse modelo de intervenção, por mais que esteja comprometido com a Saúde do Trabalhador, só é possível em um serviço subutilizado. A divulgação, no caso, apenas contribuiria para um colapso. Isso reforça, portanto, a impor tância de um comprometimento não apenas ideológico com o campo - estar ao lado dos trabalhadores -, mas também apropriação de sua proposta metodológica, que requer ações mais focadas no campo macro, e algumas intervenções específicas, de casos mais críticos, no âmbito individual.

O tema da Saúde Mental \& Trabalho se confirma como uma demanda presente também nos psicólogos que atuam em Saúde do Trabalhador, seja no estabelecimento do nexo causal, na assistência, na intervenção na vigilância, como na sensibilização da equipe e da rede para as questões de sofrimento psíquico. Os psicólogos apontaram estratégias interessantes referentes a esse tema. A promoção de espaços dentro do CEREST para acumular, discutir estudos de caso, sensibilizar o restante da equipe para reconhecimento do nexo parecem iniciativas importantes. No que tange a uma elaboração mais técnica, a demanda por protocolos que auxiliem a intervenção é uma demanda apontada por alguns respondentes do questionário. Não se pode esperar que um protocolo de investigação técnico seja capaz de emitir um laudo para explicar e diagnosticar o ambiente de trabalho e o trabalhador. O mapa de riscos do MOI apresenta a necessidade da escuta do trabalhador. A combinação de um protocolo que auxilie na investigação de nexo com a capacitação para que os profissionais, em geral, consigam analisar as relações sociais e o impacto no psíquico parece ser o mais apropriado.

\section{Nota}

1 Lacaz, F. A. D. C., Machado, J. M. H., \& Porto, M. F. S. (2002). Estudo da situação e Tendências da Vigilância em Saúde do Trabalhador no Brasil. Relatório de Pesquisa. Rio de Janeiro, 2002. (Mimeo). 


\section{Referências}

Bock, A. M. (1999). A Psicologia a caminho do novo século: identidade profissional e compromisso social. Estudos de Psicologia 4(2), 315-329.

Coelho-Lima, F. (2013). A Psicologia do Trabalho e das Organizações na formação do psicólogo no Brasil. Dissertação de Mestrado, Programa de Pós-graduação em Psicologia, Universidade Federal do Rio Grande do Norte, Natal, RN. Recuperado de http://repositorio.ufrn. br:8080/jspui/bitstream/123456789/17531/1/FellipeCL_DISSERT.pdf

Conselho Federal de Psicologia - CFP. (2019). Saúde do trabalhador no âmbito da saúde pública: referências para atuação da(o) psicóloga(o) [recurso eletrônico. Brasília: Autor.

Dimenstein, M. (2001). O psicólogo e o compromisso social no contexto da saúde coletiva. Psicologia em Estudo, 6(2), 57-63.

Diogo, M. F. \& Coutinho, M.C. (2013). Ser psicóloga no Brasil: entre o exercício profissional e a realização de atividades domésticas e de cuidado não remuneradas. In L.A. Llhullier (Org.),Quem é a Psicóloga brasileira? mulher, Psicologia e Trabalho (pp. 107-128). Brasília, DF: Conselho Federal de Psicologia.

Gondiim, A. V. B., Bastos S.M.G., \& Peixoto, L.S.A. (2010). Áreas de atuação atividades e abordagens teóricas do psicólogo brasileiro. InO trabalho do psicólogo no Brasil(pp. 174-199). Porto Alegre: Artmed

Heloani, J. R. M., (2005). Psicologia do Trabalho ou do Capital?...eis a questão.Revista Psicologia Política, 5(10), 297-312.

International Labour Organization - ILO. (2019). Safety and health at the heart of the future of work. Genebra. Recuperado de https:/www.ilo.org/wcmsp5/groups/public/---ed protect/--protrav/---safework/documents/publication/wcms_687610.pdf

Imbrizi, J.,Keppler, I.L.S., \& Villhanu eva, M.S. (2013). Grupo dos Novos: relato de uma experiência de estágio com grupos de acolhimento de trabalhadores em um Centro de Referência em Saúde do Trabalhador (Cerest). Rev. Bras. Saúde Ocup, 38(128), 302-314.

Jacques, C. C. (2009). Proposição de um instrumento com indicadores nacionais para monitoramento dos CEREST. Dissertação de Mestrado, Programa de Pós-graduação em Saúde Pública, Fundação Oswaldo Cruz, Escola Nacional de Saúde Pública Sergio Arouca. Rio de Janeiro, RJ, Brasil.

Jacques, M.G. (2007). O nexo causal em saúde/doença mental no trabalho: uma demanda para a psicologia. Psicologia \& Sociedade, 19(1), 112-119.

Lacaz, F. A. C. (1996). Saúde do Trabalhador: um Estudo sobre as Formações Discursivas da Academia, dos Serviços e do Movimento Sindical. Tese de Doutorado, Programa de Pós-graduação em Medicina, Universidade Estadual de Campinas, SP.

Lacerda, F. (2013). Capitalismo dependente e a psicologia no Brasil: das alternativas à psicologia crítica. Revista Teoria y crítica de la psicologia, 3, 216-263. Recuperado de https://dialnet. unirioja.es/servlet/articulo?codigo $=5895413$

Lhullier, L. A. \&Roslind 0, J.J. (2013). As psicólogas brasileiras: levantando a ponta do véu. In L. A. Lhullier (Org.),Quem é a Psicóloga brasileira? Mulher, Psicologia e Trabalho (pp. 2762). Brasília, DF: Conselho Federal de Psicologia.

Lourenço, E.A. S (2013). Alienação e Agravos à Saúde dos Trabalhadores no Setor Sucroenergético. In E. A. S Lourenço \&V. Navarro (Orgs.), O Avesso do Trabalho III (pp. 165-198). São Paulo: Outras Expressões.

Macêdo, K. B., Heloani, R., \&Cassiolato, R. (2010). O psicólogo como trabalhador assalariado: setores de inserção, locais, atividades e condições de trabalho. In A. V. Bastos, S. M. Gondim et al. (Orgs),O trabalho do psicólogo no Brasil (pp. 131-150). Porto Alegre: Artmed. 
Machado, J.M. H., Santana, V. S., Campos, A.Ferrite, S., Peres, M. C., Galdino, A. et al. (2013). Situação da Rede Nacional de Atenção Integral em Saúde do Trabalhador (Renast) no Brasil, 2008-2009. Revista Brasileira de Saúde Ocupacional, 38(128), 243-256.

Minayo-Gómez, C. M., Machado, J. M. H., \& Pena, P. G. L. (2011). Introdução. In Saúde do trabalhador na sociedade brasileira contemporânea (pp. 23-34). Rio de Janeiro: Editora Fiocruz.

Oddone, I.,Marri, G., Gloria, S.,Briante, G.,Chiattella, M., \& Re, A. (1986). Ambiente de Trabalho: A Luta dos Trabalhadores pela Saúde. São Paulo: Hucitec.

Paparelli, R., Sato, L., \& Oliveira, F. (2011). A saúde mental relacionada ao trabalho e os desafios aos profissionais da saúde. Revista Brasileira de Saúde Ocupacional, 36(123), 118-127. Sato, L., Ribeiro, H. P., Castro Lacaz, F. A., Clemente, C. A., \& Dutra, P. (2002). Entrevista: Herval Pina Ribeiro, Francisco Antonio de Castro Lacaz, Carlos Aparício Clemente e Pérsio Dutra falam sobre a história do DIESAT. Cadernos de Psicologia Social do Trabalho, 5, 63-85. https://doi.org/10.11606/issn.1981-0490.v5i0p63-85

Sato, L. \& Bermardo, M. H (2005). Saúde mental e trabalho: os problemas que persistem. Ciência e Saúde Coletiva, 10(4), 869-878

Sato, L.\&Lacaz, F. A. C. \& Bermardo, M. H. (2006) Psicologia e Saúde do Trabalhador: práticas e investigações na Saúde Pública de S.Paulo. Estudos de Psicologia (Natal), 11(3),281-288. Santos, A. P. L. D.\&Lacaz, F. A. (2011). Saúde do trabalhador no SUS: contexto, estratégias e desafios. In C. Minayo-Gomez, J. M. Machado, \&P. G. Pena (Orgs.), Saúde do trabalhador na sociedade brasileira contemporânea (pp. 87-105). Rio de Janeiro: Editora Fiocruz.

Silva, M. P., Bernardo, M. H., \& Souza, H. A. (2016). Relação entre saúde mental e trabalho: a concepção de sindicalistas e possíveis formas de enfrentamento. Revista Brasileira de Saúde Ocupacional, 41, e23. EpubDecember 12, 2016. https://doi.org/10.1590/2317-6369000003416 Yamamoto, O. H. (2007). Políticas sociais, "terceiro setor" e "compromisso social": perspectivas e limites do trabalho do psicólogo. Psicologia \&Sociedade, 19(1), 30-37. https://doi. org/10.1590/S0102-71822007000100005

\section{ISABEL LOPES DOS SANTOS IKEPPLER \\ http://orcid.org/OOOO-0002-3462-5223}

Doutoranda da Pós-graduação em Psicologia, Universidade Federal do Rio Grande do Norte.

Endereço: Universidade Federal do Rio Grande do Norte, Campus Universitário, Centro de Ciências Humanas Letras e Artes, Departamento de Psicologia, sala 614, Lagoa Nova, Natal, RN, Brasil 59078-970, caixa-postal 1622.

E-mail: bel.keppler@yahoo.com.br

\section{OSWALDO HAJIME YAMAMOTO}

http://orcid.org/0000-0001-7870-5666

Docente do Departamento de Psicologia, Universidade Federal do Rio Grande do Norte.

E-mail: oswaldo.yamamoto@gmail.com 


\begin{tabular}{|l|l|}
\hline \multirow{3}{*}{ Histórico } & $\begin{array}{l}\text { Sulbmissão: 28/09/2019 } \\
\text { Revisão: 15/06/2020 } \\
\text { Aceite: 21/07/2020 }\end{array}$ \\
\hline \multirow{3}{*}{ Contribuição dos autores } & $\begin{array}{l}\text { Concepção: ILSK, OHY } \\
\text { Coleta de dados: ILSK } \\
\text { Análise de dados: ILSK, OHY } \\
\text { Elaboração do manuscrito: ILSK } \\
\text { Revisões críticas de conteúdo } \\
\text { intelectual importante: OHY } \\
\text { Aprovação final do manuscrito: } \\
\text { ILSK, OHY }\end{array}$ \\
\hline Consentimento de uso de imagem & Não se aplica. \\
\hline Aprovação, ética e consentimento & Não se aplica. \\
\hline Financiamento & Bolsa DS/CAPES. \\
\hline
\end{tabular}

